\title{
SUBJECTS ।
}

A CONSIDERATION OF TIE ETHICS OF ARISTOTLE AND KANT*

\author{
Jin K. Swindler
}

My purpose is to explore a few interconnected aspects of five chief problems in moral theory the nature of moral agents, whether there can be a universal and necessary moral principle, the need for motaphysical freedom in ethics, moral freedom proper, and the end of morality. The discussion turns around the necessary conditions for explanations of moral behavior. Throughout I take as my strongest adversary the moral theory of Kant and as my chief council the ethics of Aristotle. though I have not hesitated to depart from the latter where it seemed appropriate. The structure of the essay is therefore openly polemical.

I understand ethics to be the science of right and wrong interaction among subjects. Since it is a science ethics does what every science does, viz. explain the behavior of its subject matter. It is therefore a good policy to lay down at the beginning what scientific explanations are so that we will know what we seek in ethics. The subject matter which ethics explains is the behavior of subjects (or, equivalently, the behavior of people qua moral agents). Since this is a study in ethics and not in logic I will only briefly otate, and without argument, what I take to be the conditions of good explanations generally,** the body of the essay, however. lies in a middle ground between logic and ethics proper, attempting as it does to contribute to the groundwork of the science.

What is understood 18 in every case a substance. Understanding is a direct and immediate relationship with substance. Explanation requires understanding and what is explained is always what follows from the characterization of a substance which supports the explanation.

* Edward S. Robinson Memorial Essay Contest Winner, University of Kansas, 1975.

* These considerations are derived from discussion with Prof. Richard Cole and from his paper "Causality and Sufficient Reason," Review of Metaphysics, Sept. 1974. lie is of course not responsible for my errors. 
This relationship between substance and what is explained requires that both be described, otherwise no logical connection between them can be made. Grounds and consequents must be characterized, and for the purposes of explanation there is no difference between a substance and its characterization, though there must be between a substance and its understanding. So we acquire the means for better explanations as we formulate better characterizations, but these better characterizations can only follow on better understanding of what is characterizedi explanation lags behind understanding and yet is driven on by it.

A good explanation is a sound argument in which (a) the major premise characterizes a class, the members of which are possible substances, (b) a minor further characterizes some of the class members as actual (this is usually implicit in $(c))$, and $(c)$ a second minor characterizes some prior state of the actual substance (this gives the middle term and answers the question 'Why (d)?'). which is the cause of (d) a posterior state of the substance which is what wanted explaining. The upper limit of good explanation is understanding. in which the formal atructure collapses into direct immediate apprehension. Understanding in this sense is beyond evaluation. What is not beyond evaluation is knowledge, for knowledge depends on explanation. It is possible to understand what cannot be known, it must even be necessary, for otherwise no knowledge would be possible. It is explanation in this vense that informs what follows. I assume that the reason such explanation is possible in ethics is that it is possible to give theoretical reconstructions of practical syllogisms.

\section{A Formal Dematerialization}

1.1. For Kant, "the most important distinction which can be considered in practical investifations" is between subjective and objective conditions of cholce (C, 27) * subjective conditions are empirical. objective conditions are rational (c, 39-40). Because of the continency of experience (for any particular subject) empirical conditions of cholce can give only prudential rules, never moral laws (C, 37) and can be the basis of only hypothetical, never of categorical imperatives $(F, 416)$. Since moral principles must be completely a priori, any admixture of empirical information degrades "their worthiness

* For economy all references are incorporated into the text. $C=$ Critique of Practical Reason (Beck $t_{r}$ ), $F=$ Foundations of the Metaphysics of Morals (Beck tr.). M = Metaphysics of Morale (Eliington tr.). $E=$ Nichomachean Ethics (Ostwald tr.). Page numbers refer to the Akademie Ed. of Kant's works and the Bekker Ed. of Aristotle's 
to serve us as supreme practical principles" ( $F, 411)$. Moral education and so moral understanding can in no way depend on "observation of onesel $f$ " or "the course of the world" (M, 216). $\Lambda$ good will must be wholly unconditioned by any object. "it contains only the form of volition in general, and this form is autonomy" (F, 444). Since morality is the law of all rational beings, rational beings must be free from empirical conditions and yet, if they are subject to duty, they must be capable of free causality $(F, 447-8)$ in the natural world. Free choice is the only moral choice and it is moral just so far as it is free from material determinations, its sole condition must be the form of universal law, "the will whose maxims are affected by [sensibility] is not a pure will" $(\mathrm{C}, 62)$ and is therefore not a moral will.

But for Kant moral choice has a material component nonetheless. The ends whose concepts lie in practical. reason (duty), and hence are opposed to ends derived from sensible impuises, are the matter of choice and the subject matter of ethics or the principles of virtue (M. 381). The ends of practical reason are necessary to choice because without them "no free action is possible" (M, 339). Ethical duties derive from the moral law's commanding the maxims of actions but not specific actions, leaving latitude for deliberation over material means ( $M, 390)$ which must also pass the test of universalizability. The ends which are also duties are "one's own perfection and the happiness of others" (M. 385). Kant can therefore accomodate the concept of a material component of choice, at least with respect to ethical duties as opposed to strict duties (in which the concept of right directly commands specific self-restraints). The highest unconditioned end of practical reason is simply virtue, which is therefore $i$ ts own end and its own reward.

I.2. It is of the utmost Importance for Kant's ethics that the purity of principles and ends be maintained. Nothing empirical can enter into either wi thout degrading their moral worth. Moral ends are the material of choice in a sense quite different from the sense in which moral principles are free of material components, the former are not empirical while the latter are understood by Kant to derive from experience. This is why moral ends but not empirical principles can be universal and necessary.

But what is entailed by all this is that Kant has driven a wedge between reason and action which may be suicidal for ethics. Kant has eliminated any material (empirical) cause in the moral personality. lle grants it a final (non-empirical) cause in its end, and a formal cause 
in the moral law. But he needs to establish its efficient causality. Since it has no empirical component, moral personality cannot be a substance in the sense in which natural objects are substances (this despite the position of personality in the table of the categories of freedom (C, 66) ). But it is in the world of natural objects that sonality must affect. Personality has nothing substantial in common with them. which removes the middle term in any practical syllogism and renders action miraculous.

$\Lambda$ Kantian might answer that the will serves to mediate between desire and duty $(M, 213)$. But the problem of personality as a whole would in that case merely shrink is still absent. What is required and what Kant's theory cannot provide is a conception of moral agency all of whose components contain a common term. If neither moral law nor moral ends have empirical components, and if these exhaustively describe moral personality, then moral personality call cause no intelligible emplrical action.

A further point, which may miss its mark in Kant but which is instructive, rests on the fact that right and wrong are correlative terms. This being so, it follows that they must flow from the same type of substance, 1.e. subjects. Any adequate characterization of subjects must be able to explain both. This in turn requires that subjects have the potential for right and wrong actions. If elther capacity were absent subjects would be essentially different, their characterization would no longer support the required explanations.

I. 3 Aristotle, on the other hand, has a theory of moral agency which provides most of the materials required for an adequate link between reason and action. The human soul has two constituents, each of which has a formal and a material component. There is a rational and an irrational part. The irrational part is composed of a wholly irrational vegetative element and an appetitive element which "partakes of reason in so far as it complies with reason and accepts its leadership" (E, 1102b). The rational part is divided into its 'ocientific' and 'deliberative elements, the former apprehending invariable principles, the latter variable principles (E, 1139a). of the four components relevant to action, the vegetative is purely material and the scientific is purely formal. Desire and deliberation, however, each have material and formal elements, which together are the origin of choice which is the efficient cause of actions "eupraxla in human conduct is not possible without thought and character... thought alone moves nothing...choice is either intelligence motivated by desire or desire operating through 
thought, and it is as a combination of these two that man is a starting point of action" (E, 1139a-b).

It is on the basis of these distinctions that Aristotle talks of moral and intellectual virtues, which are the conceptual source of the practical syllogism. The empirical element in moral virtues is their source in habituation: even intellectual virtues are grounded in experience $(E, 1103 a)$, "In a word, characteristics develop from corresponding activities" (E, 1103b). Moral habituation is a matter of coming to feel pleasure at the right objects ( $E, 1104 \mathrm{~b})$. The excellence of the deliberative function is practical wisdom, and "practical wisdom has as its object the ultimate particular fact, of which there is perception but no scientific knowledge" (E, 1142a). It is because $n$ ristotle includes material (empirical) grounds in the determination of both desire and deliberation that, he can account for action, he has in effect removed the wedge that Kant insists on driving between reason and action. He has provided the common term in all the conditions and consequences of choice which makes an intelligible conception of moral agency possible. This term is in effect substance, a principle of unity which Kant applies to natural objects but with which he refuses to unify moral personality with its natural correlates. This, it seems to me, is the Aristotelian answer to both Kant and Hume on the matter of the causality of reason.

\section{A Maximal Dilemma}

II.1: In practical problems, says Kant, what is alone important is that there be "some speclfic determination." without which "the problem cannot be solved" (c, 25). For this reason no principle which relies on merely contingent (empirical) conditions can serve as a practical principle, for every contingent result cannot be determined beforehand. Thus, Kant believes that the categorical imperative is adequate to solve specific practical problems, for it alone among imperatives can be stripped of material content $(F, 421)$. So strong is $h$ is demand for purity here that he claims that the categorical imperative "must completely deterinine the will as will, even before $I$ ask whether $I$ am capable of achieving a desired effect or what should be done to realize it" (c, 20).

The categorical imperative, with respect to ethical duties, commands maxims but not actions (M, 392), and its first formulation commands the conformity of maxins with the idea of universal law ( $P, 421)$. This seems the most fundamental and Kant's most favored formulation, for from 
it the others follow. That the concept of law (the categorical imperative is the practical law) is synonymous with the concept of universality makes the judgment "a practical law which I acknowledge as such must qualify for being universal law... an identical and the refore a self-evident proposition" $(C, 27)$. Indeed, the "type" of the moral law is simply the form of natural law (c, 69). so that the form of the imperative is supposed to mediate between it and a proposed maxim.

"A maxim is the subjective principle of acting which contains the practical rule which reason determines according to the conditions of the subject (often its ignorance or inclination) and is thus the principle according to which the subject acts" (F, 42In). A will is described but is not determined by its maxims, a good will as such is one all of whose maxims are universalizable, and is therefore wholly determined by the moral law; an evil will as such is one none of whose maxims are universalizable, and which is therefore not determined by the moral law at all but wholly by inclination. $A$ maxim is moral just in case it can be a universal rule.

II.2.

Kant would therefore no doubt agree that if it could be shown that no maxim can be a universal rule then either there can be no moral maxims or moral maxims need not be universalizable. Such a demonstration would also show that universalizability of maxims cannot be the supreme principle of morality. I assume that there are moral rules.

A maxim not only describes a will but also an action (c. 60), a subject is what it does. It is this description which is to be tested for its universalizability. Any such description must be either of a class of identical or non-identical acts. If it describes identical actions. the maxim's range is merely those actions and no different actions, and hence only those subjectsi it can never apply to a subject with another identity. i.e. who acts differently. If the maxim describes non-identical actions. it is not the maxim of this action that is being tested, but only one of its components (Kant thinks its abstracted form), viz. that feature common to all actions of this type. If the entire maxim of this act is to be tested it is necessary to revert to the first alternative, viz. that it is only identical actions of identical subjects that are being examined. Either it is the maxim of this act which is being tested or it is not. If it is, the whole maxim must be tested and not only part of it (its form): in which case, if it is universalizable it is so because it is identical in detail to all the actions of its type and in effect defines that class (in much the 
way a description of 2 defines 2 in all its occurences). If it is not the entire maxim of this action which is being tested, it is simply not a test of this action. The latter alternative defeats the purpose of the test, the former is not a test of the required type, viz. of the universalizability of the maxim over different aotions. Even if Kant is right in his criticism of the indeterminacy of material principleg, it looks as if his own highest moral principle has the same difficulty.

A Kantian rejoinder to this reductio might be that the categorical imperative was never meant to be completeiy determinate for specific actions, that in fact, with respect to positive virtues at least, non-mechanical judgment (requiring understanding but not imagination $(c, 69)$ ) about means is required. Buts (1) this seems to amount to a denial that Kant's moral law is any more determinate than the Epicurean, (2) whatever means are considered to achieve some end, they will require formulation in a maxim and testing against the categorical imperative to determine whether they are forbidden, which would make them susceptible to the maximal dilemma; (3) even if the categorical imperative dictates my own perfection and the happiness of others, it is the detail of involved characters which determines what can count as perfecting myself and whether others are worthy of the happiness I can give them, which detail, being unique to individuals. wili in effect require more or less principleless judgment.

II.3. The dilemma is not insurmountable. Its source is the demand for universality in moral principles and the consequent construal of universalizability as the moral law. Universality is only one part of moral law, and not its chief part. Aristotle begins his study of ethics with a similar disclaimer, the subject and basis of discussion "hold good only as a general rule, but not always" a complete demonstration of the rightness of an act (or its wrongness) is out of the question, "the agent must consider on each different occasion what the situation demands" $(E, 1094 \mathrm{~b}, 1103 \mathrm{~b}-1104 \mathrm{a})$. Hence practicai wisdom. in the sense of moral virtue (good character) and savoir-faire, become constitutive and exhaustive of moral well-being (eupraxia). But practical wisdom can never attain the status of a science, for its subject matter is variable, and error is possible even on the highest level.: "The ultimate particular fact of which there is perception but no scientific knowledge" is the sine qua non of morality (E, 1142a). He goes so far as to hold that moral truths must be confirmed by "the actual facts of 11 fe" (E, 1179a). Such truths would clearly count only as counseis for Kant and not as laws (F, 416) and could never ground more than hypothetical imperatives. 
I1.4. There is a relation of four ideas which is decisive for the differences between Kant and Aristotle pointed out in these first two sections. The relation is this: moral laws are (1) universal just in case they are (2) necessaryl they can be necessary just in case they can apply to (3) metaphysically free subjectsi and they can apply to such subjects just in case those subjects are (4) dis-unified. Kant accomodates the universality of law but his moral agents are dis-unified. Aristotle has the concept of a unifled subject, but he denies the universality of moral law. It is for the sake of the metaphysical freedom of the agent that Kant insists on universality, for he belleves (rightly) that only free agents can be moral. Aristotle sees the theoretical need for a concept of moral freedom, but he is able to provide one and maintain the unity of the subject as well, though he forsakes universality and necessity into the bargain.

\section{Free You Are if You Think You Are}

III.I.

The foundation of Kant's moral theory is the concept of freedom (C, $46 \& \mathrm{~F}, 447$ ) or autonomy. He defines freedom negatively as "independence from the determining causes of the world of sense" (F, 452 \& $C, 29)$. "Autonomy of the will is that property of it by means of which $1 t$ is a law to 1 tself independently of any property of objects of volition", heteronomy results if the will "goss outside itself and seeks [its] law in the property of any of its objects" (F, 440-441). Autonomy is then identified as "the sole principle of all moral laws and of the duties conforming to them," while heteronomy "not only does not establish any obligationg but is opposed to the principle of duty and to the morality of the will" (c. 53). It follows for Kant that the moral will must be determined prior to its apprehending any object of experience ( $c, 31,57-58)$. In fact, he claims. "the will is never determined directly by the object and our conception of $i t$, rather, the will is a faculty which can make an object real" (c, 60).

Juxtaposed with the concept of an object of experience as a member of a determined causal sequence, this concept of freedom gives rise to the problem of making the autonomous will intelligible as the cause of any temporal objoot, in this case an action. Free will cannot be causaliy determined and can thereforo nevor be underatood as part of such a sequence. But it is only as free that a will is moral. There is thus a logical hiatus between the moral will and its objects. Indeed, Kant insists that the objective reality of freedom "can never be comprehended or even imagined" ( $F, 459)$, that "freedom of an efflelent cause cannot be comprehended" (c, 94). 
Kant's resolution of this difficulty is to understand the will and its objects as belonging to separate 'worlds,' one intelligible the other sensible (F, 451452). which can never, because they are logically dis.: tinct, give rise to the contradiction of the first Critique's third antinomy. This resolution gives the negative concept of freedom as the will's independence from determination by empirical objects. But that is insufficient for morality, what is required is a positive concept of the autonomous will as an efficient cause.

This is provided by the autonomy expressed in the principle of morality and the "consciousness of freedom of the will" (C, 42). It is this consclousness of freedom and of determinability by nothing but the moral law that makes us moral agents and "transfers us into an intelligible order of things." The concept of practical reason is thereby transforined from its transcendent to its immanent significance (C, 16,48), though not in a speculative but only in a practical way.

What Kant has sacrificed for this concept of metaphysical freedom is the unity of the moral agent and with it the possibility of understanding a moral personality as a cause of action, both of which he admits. There are, however, other consequences. For example, it is impossible to understand why evil could ever be imputed to a subject, since Kant agrees that a metaphysically free subject must have "the capacity (facul1.as) to overcome all opposing sensible impulses" ( 1.397$)$. Indeed, if such strength of will is granted, weakness of will seems to be a mere illusion.

III.2 Aristotle seems to have foreseen at least some of these difficulties and to have provided a concept of moral freedom (voluntariness) which is adequate for explanation without sacrificing the unity of the moral agent. He agrees with Kant that heteronomy results in the negation of freedom (E, 1110a). But what counts as he teronomy is the subject's being physically constrained to behave in a certain way. He allows that the re are mixed cases in which material circumstances combine with a subject's desires and give rise to only partially autonomous behavior. The term voluntary is to be used "where the source of motion is within oneself, it is in one's power to act or not to act" (E, 1110a): Clearly what is meant by "within oneself" is "within one's physical dimensions' and not merely "within one's inind (reason).'

It is however, not material constraint but the effect of incilination that is most decisive for Kant's placing the source of action in the subject's will (practical rea- 
son). The consequence of his doing so is that action caused by inclination is not free action. Aristotle sees the problem! "do we perform noble acts voluntarily and base acts involuntarily? The latter alternative is ridiculous, since the cause in both cases 18 one and the same... It is... wrong to call involuntary those acts which are due to passion and appetite" (E, Ilila). The reason for all this is that "the irrational emotions are considered no less a part of human beings than reasoning is" (E, 1111b).

III.3. The moral problem of freedom is simply to discover how a subject can himself determine his action and be responsible for it, and therefore morally good or bad. Kant's resolution clearly does not solve thls problem because the relation between the agent (moral personality) and his action is ineffable due to the radical disunity within the person himself. iny solution to the problem of moral freedom which can ever be intelligible must maintain the unity of the human subject. What is required is that we understand reason (in Kant's sense) as just one among many dimensions of a common continuum and thereby close the hiatus between the form and matter. of the subject. Moral subjects must be substantial causes to be both efficient causes of action and autonomous. i.e. to be subjects at all.

Everything with substantial exlstence determines its own behavior to some degrees every event is partially the result of the nature of the thing of which the event is a determination. If reason is the only formal property of subjects, then, as Kant supposes, a subject is autonomous just so far as his reason is the cause of his action. But reason is not the only formal property of subjects. nor can it be $i$ for in that case they could not be agents at all, a fortiori they could not be subjects. What Kant thinks are material (empirical) determinates of action, viz. inclinations, are in fact formal properties of the character of subjects. In so far as actions are determined by any component of character, whether reason or inclination, they are autonomous actions.

Moreover, choice, so far as it is free, ia no more undetermined than any other variable in the concept of action. Choice is morally free just in case and just so far as it derives from the nature of the choosing subject. $A$ subject whose cholce is wholly determined by another is not free, but this is an impossible limiting case since the nature of the subject necessarily enters into the determination of its action. If we are not to allow that the determination of action by the subject's nature is to count as its freedom, then we must say that nothing, neither temporal nor a-temporal, can ever be free. But if 
we allow the freedom of a-temporal subjects because of their self-determination, for the same reason we must allow the freedom of temporal subjects. If freedom is just autonomy, everything that is a determinate thing is free to some degree because it is partially determined by what it is. It is not whether humans are free that can be questioned, but how free they are, and that varies, as Aristotle says, "with reference to the moment of action" (E, 1110a).

Moral strength, can be understood as a composite immanent capacity to withstand external influence without external determination, moral strength is nothing other than freedom and varies from subject to subject and time to time. Moral virtue is gounded in the same capacity: If a subject is determined only by his irrational inclination (per impossibile) Irrespective of external influence, he is just as free as he is if determined only by his reason (also per impossiblle). The task of moral education is to make one's inclinations and one "s reason, i.e. one'g character, tend toward the good. not to eliminate the effect of the existence of either. Good character (moral virtue and practical wisdom) is both the source and the goal of moral action. The reason that the good for man is composite is not only (though importantly) that it must be completely satisfying for any man (see Plato's Philebus), but more importantly, that freedom must underpin morality and freedon requires the composite substantial subject.

\section{What Purpose in Thls Veil of Tears?}

IV.1. Kant seems to agree that human beings are purposive creatures. but he often talks as if they could act without purposes. Indeed, it is an inevitable and characteristic feature of his moral theory that rational beings (1ike objects of beauty in the third Critique) are in effect "purposive beings without purpose." He insists that all subjective (materlal = empirical) ends be eliminated from the motive of action, that moral agents as such have no eubjective incentives ( $F, 427)$. Since an end for action is still required, he locates this objective end in "rational nature." which is the only "end in itself" (F, 429). This identification of rationality as the end in itgelf provides the required mediation between the first and the second and third forms of the categorical. imperative (F. 431). The moral law makes reference neither to any external purpose (F, 415) nor to any expected result of action $(F, 402)$. Haterial ends can yield only hypothetical imperatives. The categorical imperative must determine the will prior to any empirical influence or any knowledge of an action's possibility (C, 18). "Pure reason 
is of itself alone practical, without any admixture of any kind of empirical grounds of determination" (c, 91). When Kant talks about the relation of the will to action his point is again that moral judgment takes nothing from sensuous nature but the mere form of lawfulness, which is "no more... than pure reason can also think for itself" (c, 71): The typic of practical reason is just the disembodied law of nature abstracted to the mere concept of law (C, 67-69). The atate of moral health is "the mind at rest." free from pathological determination. 'apathy' in its etymological significance (M, 408-409).

IV . 2

Aristotle's position, again, is quite different and quite pedestrian compared to Kant's. The proper end of moral action for Kant is clearly an a-temporal. non-spatial object, the pure will, Aristotle disagrees s "the good which we have been seeking is a human good and the happiness a human happiness" (E, 1102a). Happiness is an action of the soul, but "the end for which an action 18 performed depends on the time at which it is done." Not only the end but the freedom of an action is relative to its temporal position (E, 1110a). What is to be done in a particular circumstance cannot be decided in advance but depends on sense perception of "the ultimate particular fact" (E, 1142a). This perception of gpatial situations underpins practical wisdom which in turn is required for the practical syllogiam ending in action (E, 1144a). Despite his denial that deliberation, the function of practical wisdom, ever determines ends ( $E$. $1112 \mathrm{~b}$ ) he rightly points out that "practical wisdom issues commands I Its end 18 to tell us what we ought to do and what we ought not to do" (E, 1143a). And the criterion for good deliberation is always success at achieving the ends which moral character providea (E, 1142b).

IV.3. To have a purpose is to be conscious of a goal. an end of action. But it is always with respect a goal. an end of action.
to his own action that a specific subject can be sald to
have a purpose. This requires self-consciousness prior to having a purpose. The self-consciousness that grounds purpose is the consciousness of one $s$ capacities, 1 .e. the range of possible actions. This amounts to an intuition of one ' $s$ own nature. But the nature of the moral subject is always composite, so that the self-consclousness underlying purpose reveals both ratlonal capacity and inclinations, $1 . e \ldots$ character.

Though self-consclousness is necessary it is not sufficient to provide actual goals, it can provide only a range of possible goals. The second condition of purposiveness is perception of an actual situation in which one of the possible actions provided by self-consciousness can become real. But this is not mere understanding of 
an actuality, for the action proposed is a future event. It therefore requires imagination which places the subject (with respect to some of his recognized capacity) in relation to a situation, which he believes will exist.

What might be called imaginative realisin together with self-consciousness provide the necessary and sufficient conditions of purposiveness. This fact implies that the having of purposes and therefore the having of moral purposes is relative to individuals in specific spatio-temporal relations. All of the myridad variables of character and situation are determinative for action because they are determinative for purpose.

What this suggests is that there are in fact two syllogisms involved in action, both of which may be called practical." The first determines ends and the second determines means. The former begins with self-consclous knowledge of one's possibilities, includes an imaginative perception of an actual situation and concludes with some one of the possible goals as actual. The latter begins with this actual goal, includes a deliberation over concrete means, and conciudes with some real action. In this way moral subjects deliberate about both ends and means. and as one consequence can be held responsible for the ends they have as well as the actions they perform ( $E$, III, 5). What subjects can't deliberate about is their capacities and character as given prior to action. Character sets possible ends, deliberation makes them actual.

The maxim of an action, for it to be the maxim of some specific action, must be descriptive of both the subject's purpose and his proposed means, for means are just proximate ends. The test whether the maxim can serve as a universal law is therefore the teat of whether the action which it describes will contradict the purpose which it includes. The contradiction by which a maxim fails to pass the test of the categorical imperative is a contradiction in purposes and is consequently dependent on the real consequences of the action it describes. If acting on a maxim would make it impossible to have the real purpose described in it, it cannot be universalized. In this way even Kant's 'ought' depends on an 'is.' In this way it is shown that the concept of real purpose is prior to the concept of the moral law.

It may now be asked whether there is some goal which is inherent in the idea of purposiveness. Selfconsciousness provides the idea of a subject as an independent entity. The concept of an absolutely independent substance is the concept of a metaphysically free substance. But such a substance, to remain independent. must be absolutely alone, it cannot come into relation 
with anything else without sacrificing 1 ts independence and therefore its freedom. Clearly then, an absolutely free being cannot be a purposive being. But on the other hand, a being with a real purpose is not completely determined by its object, for its object, as goal, is partly determined by it. In so far as it is a goal it is taken up as a project and thereby made a part of the subject's character. To have a real goal is to assimilate part of the world to oneself. By having a purpose a subject enforces its freedomi it creates its independence by structuring the world after its own character. To deny that one is free is therefore to deny that one has goals, that one is a purposive being. Freedom is just purpose succeeding.

But success is always the actualizing of a subject's capacities: so freedom is the process of making oneself real. We may call this process 'perfection,' and take it that the purpose prescribed by self-consclousness is subjective perfection. This is the ground of the truth that all men seek the good, for it is clear that all selfconscious oubjects must seek what they take to be their own perfection. Moreover, Individual perfection must comprise the actualization of character, intelligence and Inclination, for these are the elemente provided by self consciousness. Freedom is in this sense actualizing one ${ }^{\prime} s$ character.

\section{Perfect Is As Perfect Does}

V.I. Almost joyously Kant proclaims that "the thought of duty...is the supreme life-principle of all human morality" (c,.86). "The highest worth which human beings can and should procure for themselves lies in intentions and not in actions only" (C, 71), the positive commands of the moral law are maxims and not actions (M, 392). Freedom as independence from the laws of nature and obedience to the self-legislated moral law within is the source of all value and the dignity of moral agents from which are derived the three primary formulations of the categorical imperative $(F, 435-436)$. The moral law itself is the fundamental object of respect and maxims are moral just so far as they agree with the moral law. Moral worth, he says, can never reside in the effects of actions, 1.e. purposes, because merely contingent results of action cannot command respect; "the pre-eminent good can consist only in the conception of the law in itself... so far as this conception and not the hoped-for effect is the determining ground of the will ( $F, 339-401)$. There is a feeling of respect for the moral law "of a kind that no man has for any inclinations whatever" (c, 92). The 
result of forming one's intentions out of respect for the moral law is identified as "contentment" to distinguish it from happiness (the agreeableness of one's subjective condition) ( $C, 117)$. Contentment is just the consciousness of virtue and virtue is the worthiness to be happy (C, 110).

But, he says, a good will is only the conditio sine qua non of morality, it is not the complete good, the remainder of which comprises happiness $(F, 396)$. The reason that happiness cannot be the supreme principle of morality is that happiness depends on a contingent subjective condition of the subject. "in the desire for happiness it is not the form but only the material which is decisive" (C. 25). N11 material practical principles depend on "the actual presence of an object" and hence "place the ground of the determination of the will in the lower faculty of desire" (C, 22). Consequently, the complete good is a synthesis of concepts none of which derive from experience, these concepts are worthiness to be happy and happiness $(C, 113 f)$.

It is understandable then how Kant can come to the peculiar conclusion that human virtue is really "moral disposition in conflict" (C, 84 and $M, 380$ ) and that "inclinations are always burdensome to a rational being" (c, 118). The effect on feeling of consciousness of the noral law, "moral feeling" properly so-called, is "merely humillation" (C. 78). Kant seems to see the ilfo of virtue as one of constant internal struggle between a moral personality proper and its material inclinations, which constitute its desire for happinese. But there. can be no duty to desire personal happiness because one cannot be constrained to want what one inherently does want (M. 386). With respect to one's subjective condition. one's duty is not happiness but perfection. "doing one's duty and...attaining the completeness of one's moral end regarding himself". $(M, 446)$, 1.e. the cultivation of one 's capacities (or natural endowments) ( $M, 387$ ). The duty to perfect oneself includes the duty to train one's inclinations so that they do not inhibit dutiful action (even though it is necessary to suppose a priori that respect for moral law is stronger than all these inclinations toward pleasure combined (M, 397, 408)). Never theless, the duty of perfecting oneself is for Kant derivative from the moral law, the moral law cannot be this duty because the moral law must, he thinks, be necessary and this duty is dependent on prior contingent conditions.

V.2. Aristotle agrees with Kant that good intentions are not the complete good, what more is required, however, is virtuous actions, for only a life of virtuous activity is a morally good life (E, 1139b). But intentions for Aristotie are neither formed nor supplied by 
reason, they are simply desires, what Kant calls inclinations. For Aristotle but not for Kant, an object of desire must be provided for there to be an intention; this is why for Kant the moral law is the only proper end of action. For Aristotle the major premise of the practical syllogiam requires that intention be determined with respect to some sensible object, it is possible for a man to "fulfill his proper function only by way of practical wisdom and moral excellence or virtue, virtue makes us aim at the right target and practical wisdom makes us use the right means" ( $E, 1144 a$ ) and the good man (which is possible for Aristotle but impossible for Kant) chooses to act "for the sake of the acts themselves.... it is virtue which makes our choice right" (E, 1144a). A good man is a man of character and Intelligence, a man of moral virtue and practical wisdom, a man whose desires or inclinations are in harmony with the way the world is at each moinent of his life. Arlstotle would not know what it means to gay desires must harmonize with reason; rather, it is both which must harmonize with the worldi "In intellectual activity concerned with action, the good state is truth in harmony with correct desire" (1139a). This is the basis of the doctrine of the mean, which is meant to specify the most general characteristic of the morally good life.

V.3. Human beings, and I suppose all conscious beings, are incapable of valuing anything higher than themselves. For value is only meaningful in correlation with purpose and purpose is consequent on apprehending one's own capacities in self-consciousness. The actualizing of one's subjective capacities is the ground of valuation and so of moral valuation, perfect subjects are the only unqualified goods, all other goods are derivative. Respect is due to subjects only so far as they are perfect, 1.e. just so far as they have actualized their real capacities, and just so far do they have dignity and justified self-esteem. The fundamental morai imperative is therefore not to wish or intend or to deoire to be perfect, but to be perfect.

But perfection 18, as Kant says, relative to subjective conditions. The imperative to be perfect is therefore not a determinative imperative for any particular subject unless the contingent facts are supplied or acquired through intuition and self-consclousness. But then the imperative is itgelf supplied in the same way, for intuition and self-consciousness give $r i s e$ to real purpose and that is just the motive to perfection. Values are thus various for various subjects and in various situations, what is common is the goal of perfection. As one lives there is a steady transvaluation of values, for which there can be no absolute scale, but which is 
determined by the combinations of values resulting from the combinations of variable characteristics of both subject and environment. What is required above all in moral problems is consciousness of all these countless factors. most of which are in fact rarely known. The standard virtues and cases which fill casuistical texts are only crude isolatjons of a few of these combinations of characteristics. A real science of morals would look rather like advanced chemistry; the ethics we have are merely alchemy by comparison.

But perhaps this is too pessimistic, and for two reasons. First, ethics as here envisioned would overlap at all points with a completed psychology; indeed ethics is just a part of psychology, for what is good for subjects is the same as what is right for them to do. Secondly, the ethics of right, at any rate, has only to do with those elements of character and the world which can be brought into harmony with each other, for purposes are the sorts of things which demand hierarchical ordering and establishing such priorities is one with bringing the subject's character into harmony.

No one can be absolutely perfect (that is just the concept of God), but anyone can perfect himself within the parameters actually obtaining. To perfect oneself is merely to mold oneself into a harmonious unity of actualizing capacities, it is not a static condition, so it cannot be merely intending what is right. Purposive beings are always in flux, the values that are possible to them are therefore in process. Subjective perfection requires consciousness of possibilities and limitations, from which flows the ordering of purposes, which constitutes the rational principle of the good iffe.

\section{University of Kansas}

